\title{
Aus dem Vorwort zur 43.-47. Auflage
}

Uberraschend schnell war die letzte Auflage vergriffen, so rasch, daß dio nëchste Auflage nicht gleich anschließend erscheinen konnte.

In der vorliegenden Auflage wurden die Texte zu vielen Stichwörtern wesentlich ausgebaut; bei einer sehr großen Anzahl von Stichwörtern wurden entsprechend dem Fortschritt des Wissens Ergänzungen vorgenommen.

$\mathrm{Zu}$ einem Teil wurden die Stichwörter neu geordnet und der deutschen Bezeichnung noch mehr als in den früheren Auflagen der Vorzug gegeben, soweit dies nicht dem ärztlichen Sprachgebrauch widersprach.

Griechisch-lateinische Bastardwörter, die sog. hybriden Bildungen, habe ich zu einem großen Teil ausgeschaltet; ganz kann man sie heute aus praktischen Gründen nicht vermeiden. Wörter wie Polyglobulie, Hyperazidität, Anazidität, Avitaminosen, afebril, Liquorrhoe, ferner horribilia wie Bartholinitis, Cowperitis u. a. werden - leider gedankenlos - jeden Tag gebraucht!

Ich bin mir darüber klar, daß man einen Teil dieser hybriden Bezeichnungen, wie z. B. Hämoglobin, Fibrinogen, Serologie u. ä., nicht mehr ausmerzen kann; genau so, wie das bei hybriden Bildungen des täglichen Lebens wie „Automobil" oder "Millimeter", unmöglich ist.

Es wird aber sicher der Tag kommen, an dem sich führende Kliniker aller Nationen zusammenfinden, um auch die Sprache der Klinik zu säubern. Das ist eine ebenso notwendige wie schwierige Arbeit, viel schwieriger als die jüngst vollendete Neuordnung der anatomischen Namen: ein mit dieser Arbeit beauftragter Kreis von anerkannten Fachleuten benötigte zur Herstellung der neuen Liste nicht weniger als $12 \mathrm{Jahre}$.

Eine nicht geringe Anzahl täglich gebrauchter Wortbildungen ist auch sachlich falsch. Auch diese müBten weitgehend durch zutreffende ersetz.t werden; ein Beispiel für viele: bei den „Vitaminen“ handelt es sich in der Mehrzahl gar nicht um Amine; A, C, D sind N-frei, nur das B.Vitamin enthält Stickstoff. E. R. RICHTER empfiehlt die Bezeichnung „Bione“ [ $\beta i o \varsigma$ Leben ], „Bion“" als „lebenswichtiges" Prinzip, das schreckliche Wort Avitaminose wäre danach durch „Dysbionose“ oder „Abionose“ [víбos Krankheit] zu ersetzen.

Berlin·Neukölln, Februar 1942. 